\title{
Effect of pectin on the composition, microbiology, texture, and functionality of reduced-fat Cheddar cheese
}

\author{
Rodrigo A. Ibáñez ${ }^{1}$ - David S. Waldron ${ }^{1}$ • \\ Paul L. H. McSweeney ${ }^{1}$
}

Received: 27 April 2015 / Revised: 8 October 2015 / Accepted: 9 October 2015 /

Published online: 28 October 2015

C) INRA and Springer-Verlag France 2015

\begin{abstract}
Hydrocolloids have been extensively studied in low-fat cheeses as a way to improve defects associated with fat reduction, which are often related to texture and functionality (meltability). Pectin is a polysaccharide obtained from plant cells and is commonly used as a stabilizer for acidified dairy beverages. This work aimed to evaluate the effect of three types of commercial pectins on the characteristics of reduced-fat Cheddar cheese during a ripening period of 180 days. Five Cheddar cheeses were made: full-fat control (FF), reduced-fat control (RF), and reduced-fat cheeses with amidated (RA), high-methoxy (RH), or low-methoxy (RL) pectin added to milk prior processing at concentrations of $0.175 \%, 0.100 \%$, and $0.075 \%(\mathrm{w} / \mathrm{w})$, respectively; levels were chosen to avoid phase separation of the casein micelles, due to depletion flocculation. Addition of amidated pectin markedly increased the moisture content of the experimental cheese $(\sim 49 \%)$, compared to $\mathrm{RF}(\sim 45 \% ; P<0.05)$. A significant reduction $(P<0.05)$ in the proportion of insoluble calcium observed in RA and RL at 180 days ( $\sim 40 \%$ versus $\sim 56 \%$ in RF) was probably caused by calcium-induced gelation mechanisms of amidated and low-methoxy pectins. Texture profile analysis showed a softening of cheeses with added pectin (hardness $<100 \mathrm{~N}$ versus $>100 \mathrm{~N}$ in $\mathrm{RF}$ at 180 days; $P<0.05)$. The melting properties of cheeses were significantly improved during ripening, although RF exhibited the lowest values (diameter increase $>85$ versus $<70 \%$ at 180 days; $P<0.05$ ). These results suggest that pectin addition can be used to modify the moisture content, texture, and melting properties of reduced-fat Cheddar cheese.
\end{abstract}

Keywords Pectin $\cdot$ Fat replacers $\cdot$ Reduced-fat cheese $\cdot$ Cheddar cheese $\cdot$ Cheese texture

Paul L. H. McSweeney

p.mcsweeney@ucc.ie

1 School of Food and Nutritional Sciences, University College Cork, College Road, Cork T12 Y337, Ireland 


\section{Introduction}

In recent years, consumers have shown an increasing interest in the consumption of cheeses with lower fat contents (Childs and Drake 2009). One of the main properties of reduced-fat cheeses is a higher protein to fat ratio that confers a more compact structure leading to a firmer and rubbery texture, lack of flavor, bitterness, development of offflavors, poorer melting properties, and a translucent appearance (Mistry 2001; Johnson et al. 2009). To compensate for the increased proportion of protein in the matrix, it is possible to increase the moisture content of the cheese by various techniques, such as the modification of processing steps or the addition of ingredients that may increase the water-holding capacity (Johnson et al. 2009).

Hydrocolloids have been used to modify the composition, and hence the texture and functionality, of reduced or low-fat cheeses. Mistry (2001) and Johnson et al. (2009) extensively reviewed the manufacture of different types of cheeses supplemented with a variety of carbohydrate-based fat replacers, such as Stellar ${ }^{\mathrm{TM}}$, Novagel $^{\mathrm{TM}}$, microcrystalline cellulose, carrageenan, gum arabic, polyanionic gum, starch, $\beta$ glucan, and gum tragacanth.

Pectin corresponds to a class of anionic polysaccharide found in the middle lamella from the cell wall of higher plants and is responsible for the firmness and structure of plant tissues, acting as a hydrating agent and providing a cementing material for the cellulose network (Thakur et al. 1997). Although pectin is found in most plant tissues, the main commercial sources of pectins are extracted from apple pomaces and citrus peels. The structure consists of a homopolymer of $\alpha-(1 \rightarrow 4)-D$-galactopyranosyluronic acid with repeating $\alpha-(1 \rightarrow 2)$-L-rhamnosyl- $\alpha-(1 \rightarrow 4)-D$-galacturonosyl sections that may contain branched sections with neutral side chains. The carboxylic groups from the galacturonans contain varying degrees of methyl esterification (DM). Pectins with more than 50\% DM are classified as high-methoxy pectin (HMP), whereas those ones with lower than 50\% DM are known as low-methoxy pectin (LMP; Thakur et al. 1997). In addition, a modified LMP may contain degrees of amidation (DA) on its carboxyl groups and is referred as amidated pectin (AMP). One of the main characteristics of pectin is its ability to form gels. In general, HMP gels under acidic conditions $(\mathrm{pH} \leq 3)$ and the presence of high concentration of sugars $(\geq 55 \%)$, where the driving forces of gelation are hydrogen bonding and hydrophobic interactions, whereas LMP gels in the presence of $\mathrm{Ca}^{+2}$, based on an egg-box model (Thakur et al. 1997). The main difference between LMP and AMP is that the latter gels at low concentrations of $\mathrm{Ca}^{+2}$.

The main application of pectin in dairy industry is to stabilize caseins in acidified milks to avoid syneresis (Maroziene and de Kruif 2000; Harte et al. 2007). Some other applications have focused the use of pectin in rennet gels (Tuinier et al. 2002; Fagan et al. 2006; Acero Lopez et al. 2009). However, the concentration of pectin in milk plays an important role in stability, due to interactions between caseins and polysaccharides. Above a certain concentration of pectin, depletion interactions may cause destabilization of milk and hence a phase separation (Maroziene and de Kruif 2000; Tuinier et al. 2002; Acero Lopez et al. 2009). Lobato-Calleros et al. (2001) successfully used LMP in milk at a concentration of $0.2 \%(\mathrm{w} / \mathrm{w})$ to increase moisture content and improve the texture of low-fat Mexican Manchego cheese, probably due to the formation of calcium pectate gels that may lead to an interruption of the compact para-casein matrix. The authors did not report the presence of phase separation in milk 
due to the interaction of pectins and caseins. However, the proportion of calcium associated with caseins plays an important role determining the texture and melting properties of cheese, and it is highly influenced by $\mathrm{pH}$ and aging (Hassan et al. 2004; Lucey et al. 2003). As the gelation of pectin has an impact on the calcium equilibrium of milk (Harte et al. 2007), cheeses made with added pectin could potentially reduce the proportion of insoluble $\mathrm{Ca}$ of cheese, leading to a weakening of the para-casein matrix and hence modify its textural and melting properties. This study aimed to evaluate the effect of different types of pectins on the composition, proportion of insoluble $\mathrm{Ca}$ and rheological properties of reduced-fat Cheddar cheese during ripening. Pectins were added into milks at concentrations below this critical point to avoid destabilization.

\section{Materials and methods}

\subsection{Pectin solutions}

One day prior cheese manufacture, solutions of amidated (AMP; 34\% DM and 15\% DA) high-methoxy (HMP; 67\% DM), and low-methoxy (LMP; 39\% DM) pectins (Herbstreith and Fox KG, Neuenbürg, Germany) were prepared at levels of $4.55(\mathrm{w} / \mathrm{v})$, $2.60(\mathrm{w} / \mathrm{v})$, and $1.95 \%(\mathrm{w} / \mathrm{v})$, respectively. Pectins were mixed with $1.5 \mathrm{~L}$ of deionized water at $65{ }^{\circ} \mathrm{C}$ for $2 \mathrm{~h}$ using an overhead stirrer to ensure complete solubilization. Pectin solutions were then cooled to $25^{\circ} \mathrm{C}$, adjusted to $2 \mathrm{~L}$, stored overnight at $4{ }^{\circ} \mathrm{C}$, and heated again at $65^{\circ} \mathrm{C}$ using a waterbath before use.

\subsection{Cheese manufacture}

Cheddar-type cheese was manufactured in the pilot plant facilities of the School of Food and Nutritional Sciences, University College Cork, Ireland. Experimental cheeses were manufactured on a $50-\mathrm{kg}$ scale based on cheesemilks standardized to a casein to fat ratio of 0.7 (full-fat, $35 \mathrm{~g}$ of fat per liter of cheesemilk) or 1.4 (reduced-fat, $17.5 \mathrm{~g}$ of fat per liter of cheesemilk) to obtain five different vats: full-fat Control (FF), reduced-fat control (RF), reduced-fat with AMP (RA), reduced-fat with HMP (RH), and reducedfat with LMP (RL). Each cheesemilk was batch pasteurized at $63^{\circ} \mathrm{C}$ for $30 \mathrm{~min}$. During this step and when cheesemilks reached $63{ }^{\circ} \mathrm{C}, 2 \mathrm{~L}$ of each pectin solution at $65^{\circ} \mathrm{C}$ was added to their corresponding vat. In order to maintain the same volume in all the treatments, $2 \mathrm{~L}$ of deionized water at $65^{\circ} \mathrm{C}$ was added to control vats (FF and RF). The final concentration of AMP, HMP, and LMP in cheese milks were $0.175 \%, 0.100 \%$, $0.075 \%(\mathrm{w} / \mathrm{w})$, respectively. These levels were selected based on preliminary work performed on $10 \%(\mathrm{w} / \mathrm{w})$ reconstituted low-heat skim milk and RF cheese milks, to maximize addition of pectin while preventing depletion interaction (Maroziene and de Kruif 2000). Once pasteurization was finished, milks were cooled to $31{ }^{\circ} \mathrm{C}$. A Cheddar cheese starter culture (R-604Y, Chr. Hansen Ltd., Little Island, Co. Cork, Ireland) was added to a level of $0.03 \%(\mathrm{w} / \mathrm{w})$ and left to ripen for $30 \mathrm{~min}$ with continuous stirring. Cheesemilks were supplemented with $0.09 \%(\mathrm{v} / \mathrm{w})$ of $1 \mathrm{~mol}^{-1} \mathrm{LaCl}_{2}$ and equilibrated for additional $5 \mathrm{~min}$. Chymosin (Maxiren 180, $180 \mathrm{IMCU}_{\mathrm{mL}}^{-1}$, DSM Food Specialties, Delft, Netherlands) was added to each vat at a level of $0.03 \%(\mathrm{v} / \mathrm{w})$ diluted one in four with distilled water to aid water dispersion. Once the curd developed 
enough firmness after $45-50 \mathrm{~min}$, the coagulum was cut and cooked from 31 to $39{ }^{\circ} \mathrm{C}$ in a period of $30 \mathrm{~min}$ and held to that temperature until the $\mathrm{pH}$ dropped to 6.2 , and the whey was drained from the vats. The curd was then cut into blocks and inverted every 15 min until the $\mathrm{pH}$ decreased to 5.4. Curd blocks were milled, salted at a level of $2.5 \%$ (w/w) $\mathrm{NaCl}$, and equilibrated for $20 \mathrm{~min}$. The salted curds were transferred to $5-\mathrm{kg}$ rectangular molds and pressed during $14 \mathrm{~h}$ at a pressure of $2.5 \mathrm{~kg} . \mathrm{cm}^{-2}$. Experimental cheeses were vacuum sealed and ripened for 6 months at a temperature of $8{ }^{\circ} \mathrm{C}$.

\subsection{Rennet coagulation properties}

The rheological properties of cheesemilks during rennet coagulation were studied with a dynamic small amplitude oscillatory rheometer equipped with a Peltier concentric cylinder system and a conical rotor (28 mm diameter and $42 \mathrm{~mm}$ length; model AR-G2; TA Instruments, Waters LLC, Leatherhead, Surrey, UK) at a frequency of $1 \mathrm{~Hz}$ and $0.1 \%$ strain. Chymosin was added to cheesemilks previously heated at $31{ }^{\circ} \mathrm{C}$ at a level of $0.03 \%(\mathrm{w} / \mathrm{v})$ and stirred for $1 \mathrm{~min}$. Two additional min elapsed between the mixing of rennet in milks and the starting of oscillation. The storage modulus (G') and the loss modulus (G') were measured during a gelation time of $45 \mathrm{~min}$. The loss tangent (LT; G'/G') was also estimated. Gelation time (GT) was defined as the time required for rennet gels to reach $\mathrm{G}^{\prime} \geq 1 \mathrm{~Pa}$. Each treatment was analyzed in triplicate.

\subsection{Compositional analysis}

Composition of cheeses was determined at 14 days of ripening. Moisture content was determined by the drying-oven method (IDF 1982), fat by the Gerber method (IIRS 1955), protein $(\% \mathrm{~N} \times 6.38)$ by the macro-Kjeldahl methodology (IDF 1986), salt by potentiometric titration with $\mathrm{AgNO}_{3}$ (Fox 1963), and calcium by atomic absorption spectroscopy (IDF 2007). The proportion of insoluble calcium (INSOL Ca) was estimated by the cheese juice extraction method at 2 and 180 days of ripening as described by Hassan et al. (2004). The $\mathrm{pH}$ was measured at $2,30,60,120$, and 180 days of ripening on a homogenized mixture of $10 \mathrm{~g}$ of cheese and $10 \mathrm{~mL}$ of water at $20^{\circ} \mathrm{C}$. All analyses were performed in triplicate.

\subsection{Microbiological analysis}

Samples were prepared as described by Fenelon et al. (2000). Starter lactic acid bacteria (LAB) were enumerated on LM 17 agar (Terzaghi and Sandine 1975) using aerobic incubation at $30^{\circ} \mathrm{C}$ for 3 days and non-starter lactic bacteria (NSLAB) were counted on Rogosa agar (Rogosa and Mitchell 1951) incubated anaerobically at $30{ }^{\circ} \mathrm{C}$ for 5 days. Enumeration of LAB and NSLAB were performed in duplicate at 2, 14, 30, 60, 90, 120 , and 180 days of ripening.

\subsection{Proteolysis}

Proteolysis was assessed by the $\mathrm{pH} 4.6$ soluble N (pH 4.6 SN/TN) method (Kruchoo and Fox 1982) and the level of total free amino acids (FAA) by the trinitrobenzenesulphonic acid (TNBS) method (Kruchoo et al. 1983) at 2, 60, 120, and 180 days of ripening. Ureapolyacrylamide gel electrophoresis (urea-PAGE) was performed directly on cheese 
samples as described by Andrews (1983) to monitor the breakdown of $\alpha_{\mathrm{s} 1}$ - and $\beta$-casein (CN) during ripening. Gels were stained with Coomassie blue G250 as described by Blakesley and Boezi (1977). Densitometric analysis of scanned gels was performed with an image processing software (ImageJ 1.48v, National Institutes of Health, Bethesda, $\mathrm{MD}, \mathrm{USA})$. All treatments were analyzed in triplicate.

\subsection{Texture profile analysis}

Texture profile analysis (TPA) was performed using a Texture Analyzer TA-XT2i (Stable Micro Systems, Godalming, Surrey, UK) at 14, 30, 60, 120, and 180 days of ripening. Cheese samples were cut into cylinders (20 mm diameter, $20 \mathrm{~mm}$ height) and stored overnight at $8{ }^{\circ} \mathrm{C}$. Cheese cylinders were compressed to $75 \%$ of strain in two consecutive cycles at a rate of $1 \mathrm{~mm} . \mathrm{s}^{-1}$. Hardness, springiness, and cohesiveness were estimated as previously described by Bourne (1978). Five cheese cylinders were analyzed per treatment.

\subsection{Meltability and release of free oil}

Melting properties of cheeses during ripening was performed by the Schreiber meltability test as described by Altan et al. (2005), by heating cheese discs at $232{ }^{\circ} \mathrm{C}$ for $5 \mathrm{~min}$. Meltability was calculated as the percentage of increase in diameter of unmelted samples. The release of free oil of experimental cheeses at $60{ }^{\circ} \mathrm{C}$ during ripening was determined by the modified Gerber method described by Kindstedt and Fox (1991). Results were expressed as the amount of free oil, as a percentage of the total cheese fat, released at $60{ }^{\circ} \mathrm{C}$. Analyses were performed in triplicate at 7, 30, 90, and 180 days of ripening.

\subsection{Dynamic small amplitude oscillatory rheology}

The rheological properties of cheese samples were determined using a controlled stress AR-G2 rheometer (TA Instruments, Waters LLC, Leatherhead, Surrey, UK) at 180 days of ripening. Serrated parallel plate geometry was used, and cheese discs ( $40 \mathrm{~mm}$ diameter, $2 \mathrm{~mm}$ height) were placed on the bottom plate at an initial temperature of $20^{\circ} \mathrm{C}$. A normal force of $\sim 1.8 \mathrm{~N}$ was initially applied to the cheese disc. Liquid paraffin was used to cover the exposed layers of the sample to prevent loss of moisture. When the normal force decreased to $\sim 0.7 \mathrm{~N}$, sample was heated to $80{ }^{\circ} \mathrm{C}$ at a heating rate of $2{ }^{\circ} \mathrm{C} \cdot \mathrm{min}^{-1}$. Analyses were performed using a total strain of $1 \%$ and a frequency of $1 \mathrm{~Hz}$, which were found to be within the linear viscoelastic region (this was confirmed by performing strain sweep and frequency sweep tests). Storage modulus (G'), loss modulus (G'), and loss tangent (LT) were measured during heating. The maximum LT ( $\left.\mathrm{LT}_{\max }\right)$, which is an indicator of melting, was also recorded. Each treatment was analyzed in triplicate.

\subsection{Color analysis}

Color of experimental cheeses was performed with a Konika-Minolta colorimeter CR400 (Konika-Minolta Optics Inc., Osaka, Japan) at 2, 14, 30, 60, 120, and 180 days of ripening. The instrument was set on the CIELAB system based on illuminant D65 and a visual angle of $2^{\circ}$. Five random measurements were performed directly on a fresh cut of cheese block at $20^{\circ} \mathrm{C}$.

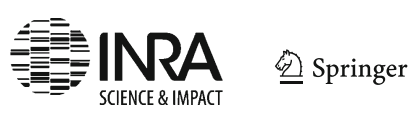




\subsection{Experimental design and statistical analysis}

Five treatments (fat content and pectin type: FF, RF, RA, RH, and RL cheeses) were manufactured in three independent trials, based on a $5 \times 3$ randomized block design. Analysis of variance (ANOVA) was performed on cheese composition, INSOL Ca, color, and rheological properties at a significance level of $P<0.05$. A split-plot design (Montgomery 2013) was used to evaluate the effects of treatment, ripening time, and their interactions on $\mathrm{pH}$, microbiological analysis, proteolysis, texture, melting, and free oil release. The ANOVA for the split-plot design was carried out using a general linear model $(\mathrm{GLM})$ procedure. If significant differences were found $(P<0.05)$, the treatments means were analyzed by the Tukey multiple comparison test. All analyses were performed using Minitab $16^{\circledR}$ (Minitab Inc., State College, PA, USA).

\section{Results}

\subsection{Rennet coagulation properties}

The rheological properties of rennet-induced gels are shown in Table 1. The addition of pectins had an effect on the gelation time (GT) and the stiffness $\left(\mathrm{G}^{\prime}\right)$ of rennet curds. Cheesemilks containing pectin had a reduction of $\sim 4$ min in GT compared to controls $(P<0.05)$. During the first $15 \mathrm{~min}$ of renneting, cheesemilks containing pectin exhibited similar increases in $G^{\prime}$ as the time increased. Beyond this time, RA increased at a slower rate than other milks (data not shown). At $45 \mathrm{~min}$, the highest G' values were found for RH and RL, followed by FF and RF and finally on RA milk $(P<0.05)$. Even though RA gel exhibited a lower LT at 45 min when compared to other treatments $(P<0.05)$, differences were lower than 0.003 units.

\subsection{Cheese composition, levels of insoluble calcium, and pH}

The composition and percentage of INSOL Ca of cheeses are shown in Table 2. As expected, a significant decrease in fat content was found between full-fat and reducedfat cheeses $(P<0.05)$. Levels of salt of experimental cheeses ranged around 1.95$2.15 \%$; however, a higher content of salt in the moisture phase of cheese $(\mathrm{S} / \mathrm{M})$ was found only in FF $(P<0.05)$, and no differences were found between reduced-fat cheeses. The addition of pectin led to an increase in the moisture content of RA, when compared to RF. No changes $(P>0.05)$ in the total $\mathrm{Ca}$ content was found between treatments when results were expressed per $100 \mathrm{~g}$ of protein. Similar levels of INSOL Ca were observed at 2 days of ripening for all treatments, which was around $60 \%-70 \%$ $(P>0.05)$. At 180 days, the INSOL Ca significantly decreased for all reduced-fat treatments $(P<0.05)$; RA and RL cheeses had a lower proportion of INSOL Ca when compared to RF $(P<0.05)$, and RH exhibited similar levels of INSOL Ca to RF, RA, and $\mathrm{RL}$ cheeses. The $\mathrm{pH}$ values of experimental cheeses during ripening are shown in Fig. 1. No significant differences $(P>0.05)$ were observed in the $\mathrm{pH}$ values of experimental treatments at 2 days of ripening. The $\mathrm{pH}$ of $\mathrm{FF}$ cheese showed no variations during 180 days of ripening $(P>0.05)$. An increase in the $\mathrm{pH}$ values was observed for other treatments after 60 days of ripening $(P<0.05)$. At 180 days, similar $\mathrm{pH}$ values 
Table 1 Rheological properties of rennet-induced gels made from full-fat control (FF), reduced-fat control $(\mathrm{RF})$, reduced-fat with amidated pectin (RA), high-methoxy pectin (RH), and low-methoxy pectin (RL) cheesemilks

\begin{tabular}{lcccccr}
\hline Item & \multicolumn{2}{l}{ Treatment } & & & \\
\cline { 2 - 7 } & FF & RF & RA & RH & RL & SEM \\
\hline Gelation time (min) & $15.03^{\mathrm{a}}$ & $14.99^{\mathrm{a}}$ & $10.90^{\mathrm{b}}$ & $10.86^{\mathrm{b}}$ & $11.30^{\mathrm{b}}$ & 0.527 \\
Storage modulus (G') at $45 \mathrm{~min}(\mathrm{~Pa})$ & $32.87^{\mathrm{b}}$ & $34.17^{\mathrm{b}}$ & $26.88^{\mathrm{c}}$ & $52.06^{\mathrm{a}}$ & $51.70^{\mathrm{a}}$ & 2.790 \\
Loss tangent (LT) at $45 \min$ & $0.244^{\mathrm{a}}$ & $0.246^{\mathrm{a}}$ & $0.238^{\mathrm{b}}$ & $0.244^{\mathrm{a}}$ & $0.242^{\mathrm{a}}$ & 0.001 \\
\hline
\end{tabular}

Gelation time corresponds to the point when gels had a storage modulus ( $\mathrm{G}^{\prime}$ ) of $\geq 1$. G' and LT were measured for $45 \mathrm{~min}$ after rennet addition. Data are means of three replicate trials. Means within the same row not sharing a common superscript differ $(P<0.05)$

were similar between RF, RH, and RL cheeses, and they were higher than those found in $\mathrm{FF}$ and $\mathrm{RA}(P<0.05)$.

\subsection{Starter and non-starter lactic acid bacteria}

The number of starter LAB exhibited a significant decrease of 2-4 log cycles for all cheeses over the ripening period of 180 days (Fig. 2a; Table 3). However, no significant differences were found between treatments (Table 3). The counts of NSLAB increased

Table 2 Composition (day 14) and proportion of insoluble Ca (days 2 and 180) of full-fat control (FF), reduced-fat control (RF), reduced-fat with amidated pectin (RA), high-methoxy pectin (RH), and low-methoxy pectin (RL) Cheddar cheeses

\begin{tabular}{|c|c|c|c|c|c|c|}
\hline \multirow[t]{2}{*}{ Item } & \multicolumn{6}{|c|}{ Treatment } \\
\hline & $\mathrm{FF}$ & $\mathrm{RF}$ & RA & $\mathrm{RH}$ & RL & SEM \\
\hline Moisture (\%) & $38.95^{\mathrm{c}}$ & $44.47^{\mathrm{b}}$ & $49.11^{\mathrm{a}}$ & $45.86^{\mathrm{b}}$ & $46.25^{\mathrm{ab}}$ & 0.924 \\
\hline Fat $(\%)$ & $31.33^{\mathrm{a}}$ & $18.78^{\mathrm{b}}$ & $15.00^{\mathrm{c}}$ & $17.66^{\mathrm{b}}$ & $17.77^{\mathrm{b}}$ & 1.550 \\
\hline Protein $(\%)$ & $23.52^{\mathrm{b}}$ & $29.40^{\mathrm{a}}$ & $29.08^{\mathrm{a}}$ & $28.28^{\mathrm{a}}$ & $29.13^{\mathrm{a}}$ & 0.640 \\
\hline Salt (\%) & $2.12^{\mathrm{a}}$ & $2.03^{\mathrm{bc}}$ & $2.14^{\mathrm{a}}$ & $1.96^{\mathrm{c}}$ & $2.09^{\mathrm{ab}}$ & 0.034 \\
\hline MNFS (\%) & $56.72^{\mathrm{a}}$ & $54.76^{\mathrm{a}}$ & $57.78^{\mathrm{a}}$ & $56.47^{\mathrm{a}}$ & $55.50^{\mathrm{a}}$ & 0.415 \\
\hline FDM (\%) & $51.32^{\mathrm{a}}$ & $33.81^{\mathrm{b}}$ & $29.48^{\mathrm{c}}$ & $33.72^{b c}$ & $32.04^{\mathrm{bc}}$ & 2.110 \\
\hline S/M (\%) & $5.46^{\mathrm{a}}$ & $4.56^{\mathrm{b}}$ & $4.37^{\mathrm{b}}$ & $4.36^{\mathrm{b}}$ & $4.43^{b}$ & 0.132 \\
\hline$a_{\mathrm{w}}$ & $0.964^{\mathrm{b}}$ & $0.968^{\mathrm{a}}$ & $0.969^{\mathrm{a}}$ & $0.970^{\mathrm{a}}$ & $0.969^{\mathrm{a}}$ & 0.0006 \\
\hline Total calcium (mg $.100 \mathrm{~g}^{-1}$ protein) & $2820^{\mathrm{a}}$ & $2869^{\mathrm{a}}$ & $2731^{\mathrm{a}}$ & $2832^{\mathrm{a}}$ & $2853^{\mathrm{a}}$ & 34.8 \\
\hline \multicolumn{7}{|l|}{$\%$ INSOL Ca/total Ca } \\
\hline day 2 & $69.89^{\mathrm{a}}$ & $65.85^{\mathrm{a}}$ & $61.83^{\mathrm{a}}$ & $60.82^{\mathrm{a}}$ & $58.65^{\mathrm{a}}$ & 1.38 \\
\hline day 180 & $57.33^{\mathrm{a}}$ & $55.89^{\mathrm{ab}}$ & $39.51^{\mathrm{c}}$ & $44.03^{b c}$ & $42.35^{\mathrm{c}}$ & 2.30 \\
\hline
\end{tabular}

Data are means of three replicate trials. Means within the same row not sharing a common lowercase superscript differ $(P<0.05)$

$M N F S$ moisture in the non-fat substance, $F D M$ fat content on a dry weight basis, $S / M$ salt in the moisture phase of the cheese, $a_{w}$ water activity 


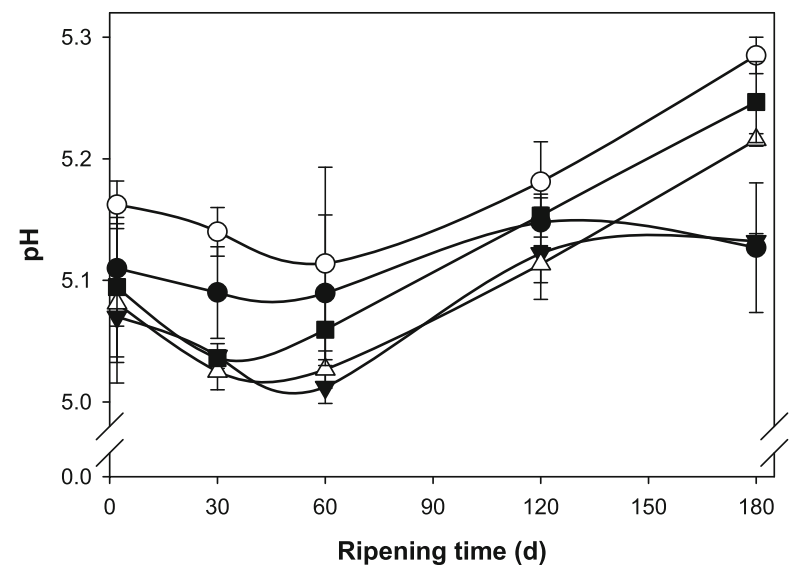

Fig. 1 Changes in $\mathrm{pH}$ during ripening of full-fat control (filled circle), reduced-fat control (open circle), reduced-fat with amidated pectin (filled inverted triangle), high-methoxy pectin (open triangle), and lowmethoxy pectin (filled square) cheeses. Values are means of three replicates. Error bars indicate standard deviation

for all cheeses during ripening (Fig. 2b; Table 3). NSLAB in FF cheese increased and reached a maximum at 14 days $(P<0.05$; Table 3$)$, remaining constant beyond, whereas the number of NSLAB in RF and cheeses containing pectin also exhibited an increased during ripening, but at a slower rate of growth, where RF, RA and RL reached a maximum at 60 days and $\mathrm{RH}$ at 30 days $(P<0.05)$, remaining constant thereafter. The number of NSLAB were similar $(P>0.05)$ between treatments at 180 days of ripening

\subsection{Proteolysis}

The primary proteolysis expressed as the level of $\mathrm{pH} 4.6$-soluble $\mathrm{N}$ of cheeses during ripening is shown in Fig. 3a, whereas the secondary proteolysis expressed as the
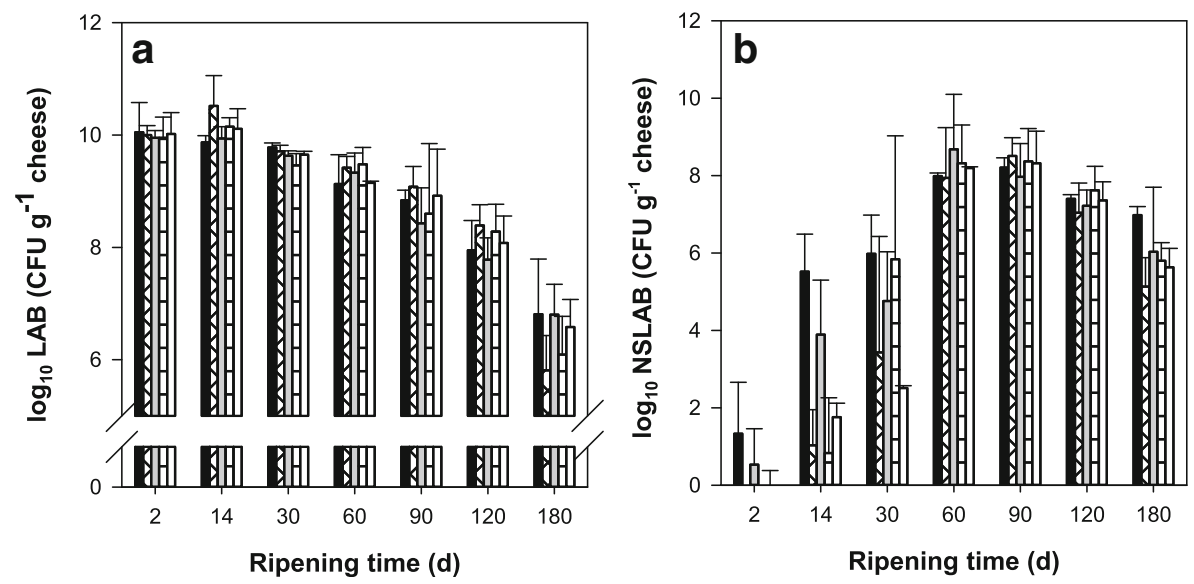

Fig. 2 Numbers of a starter (LAB) and $\mathbf{b}$ non-starter lactic acid bacteria (NSLAB) during ripening of full-fat control (black bars), reduced-fat control (white bars filled with perpendicular lines), reduced-fat with amidated pectin (gray bars), high-methoxy pectin (white bars filled with parallel lines), and low-methoxy pectin (white bars) Cheddar cheeses. Values are means of three replicates. Error bars indicate standard deviation 


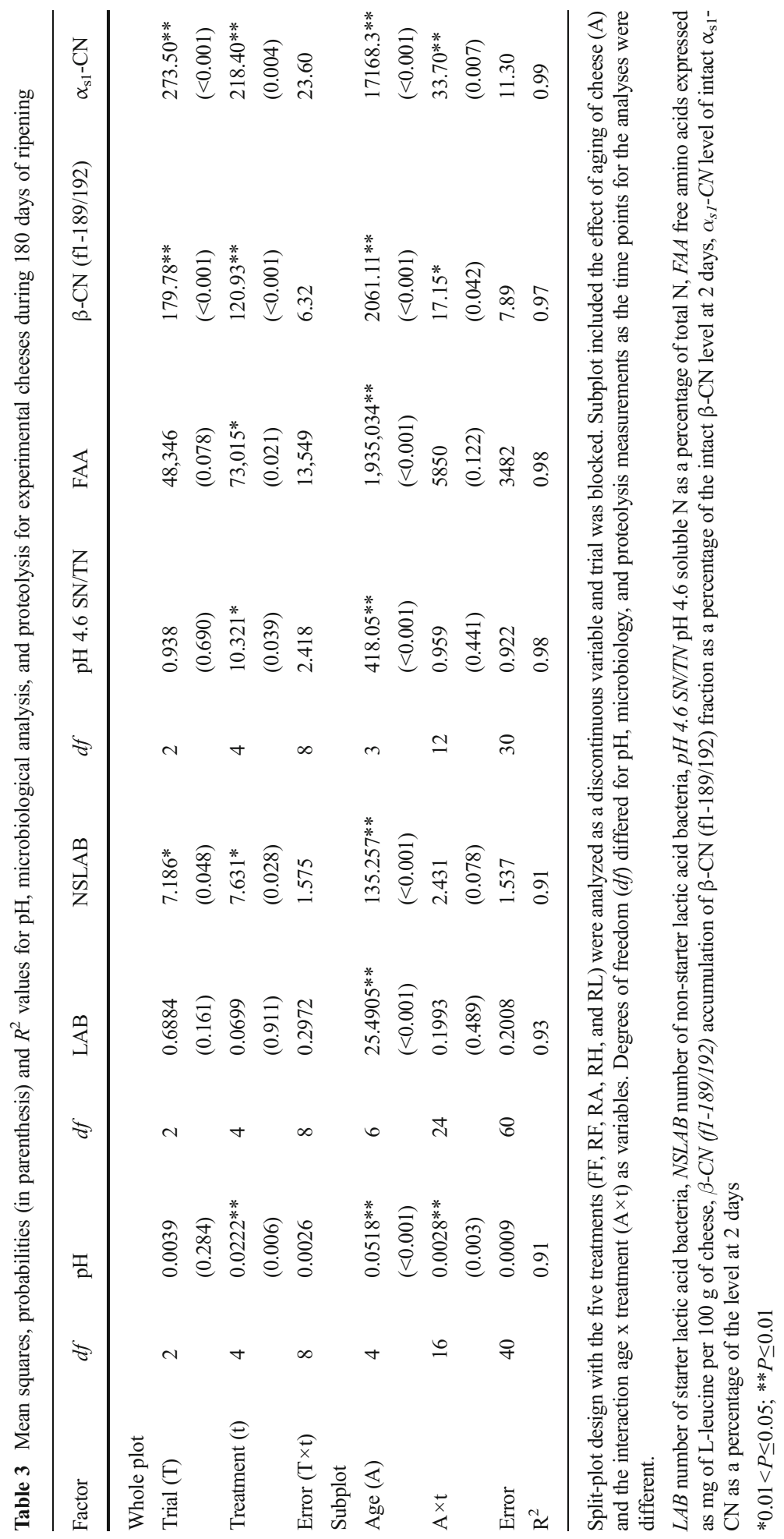



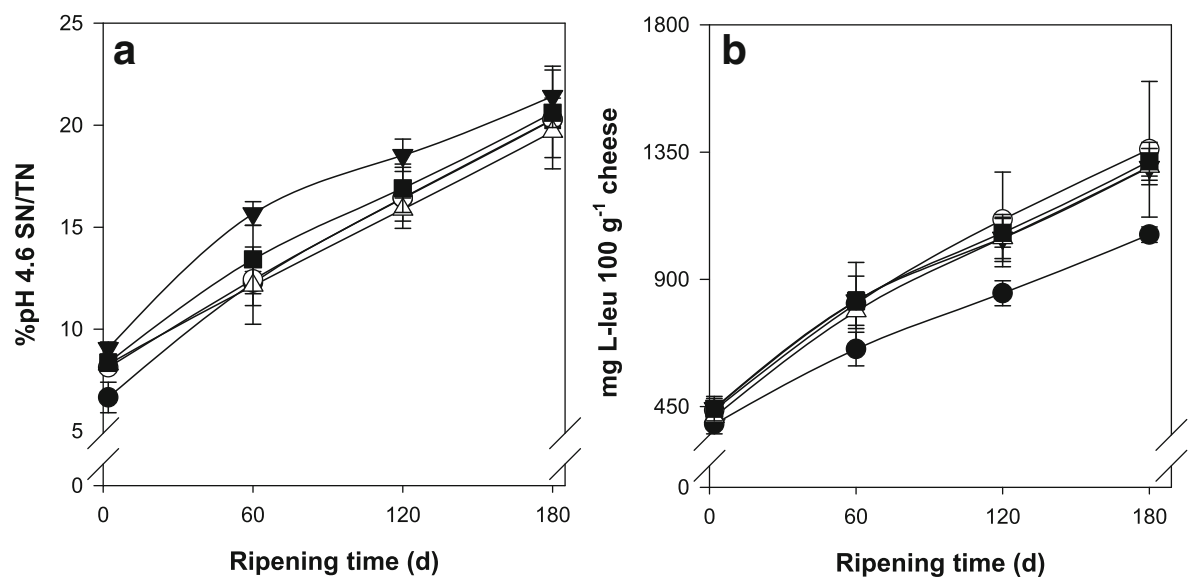

Fig. 3 Changes in a $\mathrm{pH} 4.6$ soluble $\mathrm{N}$ as a percentage of total $\mathrm{N}$ and $\mathbf{b}$ free amino acids expressed as $\mathrm{g}$ of Lleucine per $100 \mathrm{~g}$ of cheese during ripening of full-fat control (filled circle), reduced-fat control (open circle), reduced-fat with amidated pectin (filled inverted triangle), high-methoxy pectin (open triangle), and lowmethoxy pectin (filled square) Cheddar cheeses. Values are means of three replicates. Error bars indicate standard deviation

concentration of total FAA is shown in Fig. 3b. A significant effect on treatment and cheese age was observed for both parameters (Table 3). A lower level of $\mathrm{pH} 4.6 \mathrm{SN} / \mathrm{TN}$ was observed for FF cheese at 2 days of ripening. Proteolysis significantly increased during ripening for all cheeses $(P<0.05)$. RA exhibited an increment of $\mathrm{pH} 4.6 \mathrm{SN} / \mathrm{TN}$ at a higher rate than other treatments $(P<0.05)$. However, no differences between treatments were observed at 180 days. A significant increase in levels of FAA was observed during ripening for all the treatments $(P<0.05)$. In addition, FF contained lower amount of FAA than reduced-fat cheeses $(P<0.05)$.

Urea-PAGE electrophoretograms of cheese samples during ripening are shown in Fig. 4. Treatments and cheese age had an effect on the breakdown of $\beta$ - and $\alpha_{\mathrm{s} 1}-\mathrm{CN}$. We observed a significant increase in levels of $\beta-\mathrm{CN}$ (f1-189/192) during ripening for all treatments (Fig. 5a; Table 3). FF cheese had significantly lower accumulation of $\beta-\mathrm{CN}$ (f1-189/192) than RF and all cheeses containing pectin $(P<0.05)$. RA exhibited higher amounts of $\beta-\mathrm{CN}(\mathrm{f1-189/192)}$ than other treatments at 60 days $(P<0.05)$ and were similar to RF cheeses after 120 days $(P>0.05)$. Degradation of $\alpha_{\mathrm{s} 1}-\mathrm{CN}$ significantly $(P<0.05)$ increased during ripening for all treatments (Fig. 5b; Table 3). RA and RL cheeses showed a higher proportion of intact $\alpha_{\mathrm{s} 1}-\mathrm{CN}$ after 120 days $(P<0.05)$, when compared to $\mathrm{FF}$ and $\mathrm{RF}$, whereas there were no differences $(P>0.05)$ between treatments after 180 days of ripening.

\subsection{Texture profile analysis}

The TPA properties of experimental cheeses are shown in Fig. 6. A significant decrease in hardness values was observed during ripening for all cheeses (Fig. 6a; Table 4). A reduction in the fat content of cheese led to an increase in hardness of RF, when compared to $\mathrm{FF}(P<0.05)$. The hardness of cheeses containing pectin was lower than that of the RF cheese $(P<0.05)$. 


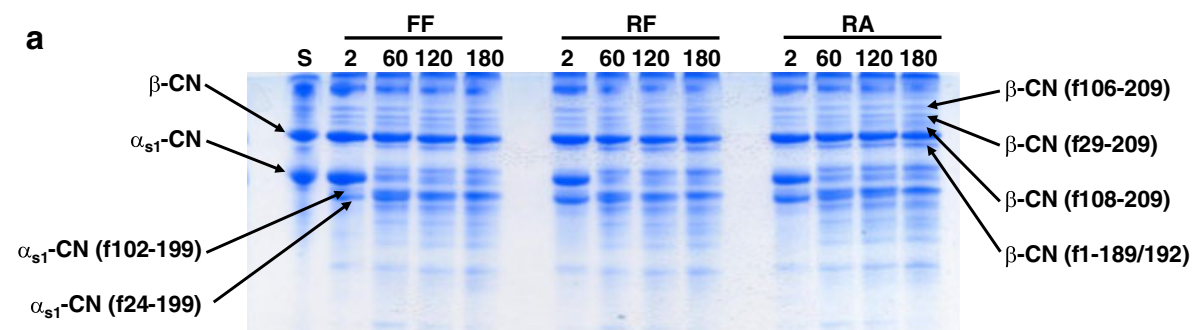

b

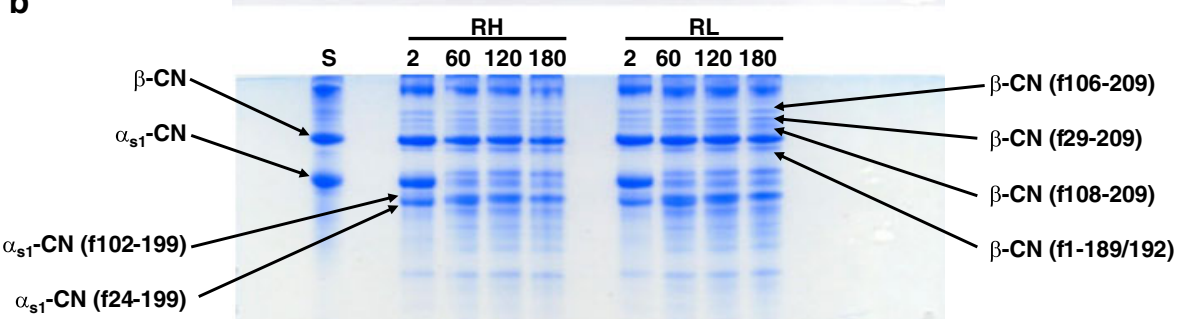

Fig. 4 Urea-Polyacrilamide gel electrophoresis of experimental Cheddar cheeses at 2, 60, 120, and 180 days of ripening of a full-fat (FF), reduced-fat (RF), and reduced-fat with amidated pectin (RA) and $\mathbf{b}$ reduced-fat with high-methoxy (RH) and low-methoxy pectin (RL) Cheddar cheeses. Sodium caseinate (S) was used as standard for each gel

The TPA springiness of experimental cheeses decreased during ripening for all treatments (Fig. 6b; Table 4). No differences between treatments were observed at 14 days of ripening $(P>0.05)$. RF exhibited a higher springiness than $\mathrm{FF}$ after 30 days $(P<0.05)$. Cheeses containing pectin had similar values than $\mathrm{FF}$ until 60 days $(P>0.05)$ and then became higher beyond $(P<0.05)$. However at 180 days, cheeses containing pectin exhibited similar values than $\mathrm{RF}(P>0.05)$.

No differences were observed between treatments in TPA cohesiveness $(P>0.05)$. Cheese cohesiveness showed a decrease during ripening (Fig. 6c; Table 4).

\subsection{Melt analysis and release of free oil}

The melting determined by the Schreiber analysis of experimental cheeses is detailed in Fig. 7a. A significant increase in melting was observed for all treatments during cheese age $(P<0.05$; Table 4$)$. At 7 days of ripening, a higher meltability was observed in FF, when compared to reduced-fat cheeses $(P<0.05)$ and similar levels of melting were observed between RF and pectin-containing cheeses. At 90 days of ripening, RA showed similar meltability than FF. At 180 days of ripening, cheeses containing pectin exhibited a higher meltability than RF $(P<0.05)$.

The release of free oil was higher in FF than all other treatments $(P<0.05)$, and only $\mathrm{FF}$ and RH exhibited an increase during ripening $(P<0.05)$. There were no differences in the release of free oil between RF and cheeses containing pectin. 

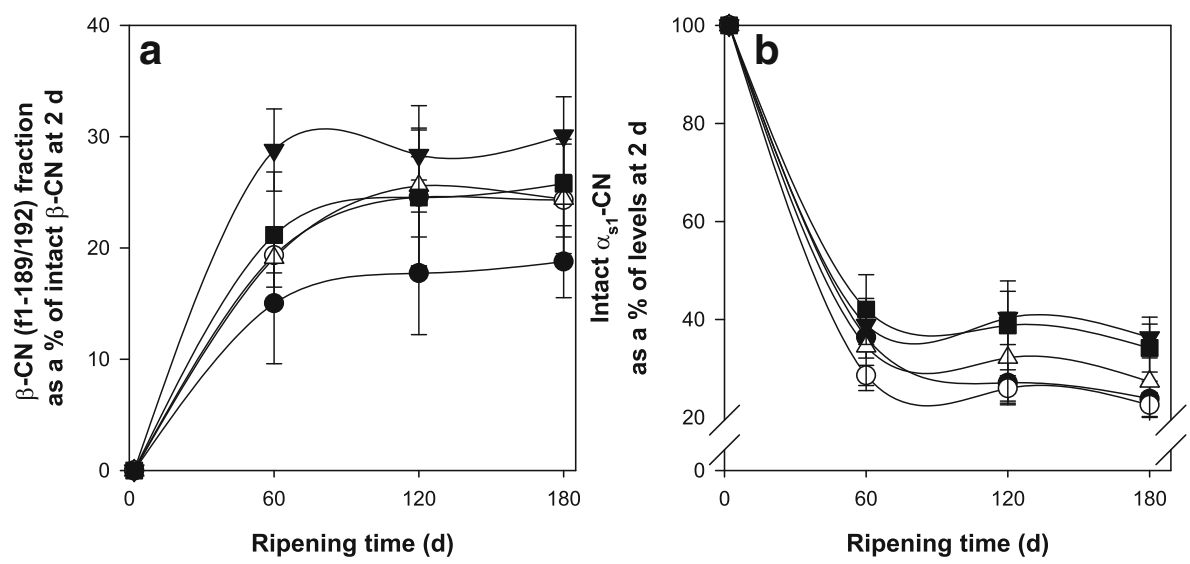

Fig. 5 Changes in a accumulation of $\beta-C N$ (f1-189/192) fraction as a percentage of the intact $\beta-C N$ level at 2 days and $\mathbf{b}$ level of intact $\alpha_{\mathrm{s} 1}-\mathrm{CN}$ as a percentage of the level at 2 days for full-fat control (filled circle), reduced-fat control (open circle), reduced-fat with amidated pectin (filled inverted triangle), high-methoxy pectin (open triangle), and low-methoxy pectin (filled square) Cheddar cheeses during ripening. Values are means of three replicates. Error bars indicate standard deviation

\subsection{Dynamic small amplitude oscillatory rheology}

The G' values of experimental cheeses showed a decrease during heating (Table 5). At $20{ }^{\circ} \mathrm{C}$, RF exhibited higher $\mathrm{G}^{\prime}$ than $\mathrm{FF}$ and pectin-containing cheeses $(P<0.05)$. At 70 ${ }^{\circ} \mathrm{C}$, no significant differences were found in $\mathrm{G}$ ' values between $\mathrm{FF}$ and $\mathrm{RF}$. RL exhibited lower $G^{\prime}$ than RA and RH $(P<0.05)$. RF exhibited lower $\mathrm{LT}_{\max }$ than FF. RL cheese had similar $\mathrm{LT}_{\max }$ than FF cheese, whereas RA and RH exhibited similar $\mathrm{LT}_{\max }$ than RF. There were no differences in the temperature of $\mathrm{LT}_{\text {max }}$ between FF, RF, and RL; however, RA and RH exhibited the $\mathrm{LT}_{\max }$ at a lower temperature $(P<0.05)$.

\subsection{Color}

The color of experimental cheeses at 14 days of ripening is detailed in Table 6. As expected, FF exhibited higher whiteness ( $\mathrm{L}^{*}$ values) than reduced-fat treatments. At 2 days of ripening (data not shown), $\mathrm{L}^{*}$ values were $\sim 88$ for $\mathrm{FF}$ and $\sim 85$ for reduced-fat cheeses. At 14 days, a decrease in whiteness was observed for all treatments $(P<0.05)$, and this difference remained at longer ripening times. No differences were observed in $\mathrm{L}^{*}$ values of cheeses containing pectin, when compared to $\mathrm{RF}(P>0.05)$. The greenness of RA and RL cheese was significantly lower (higher a* values) than RF $(P<0.05)$ and similar to FF. The addition of pectin had no effect on cheese yellowness $\left(b^{*}\right.$ values; $P>0.05)$.

\section{Discussion}

A reduction on the GT during renneting of cheesemilks supplemented with pectins is associated with an increase in the viscosity of the aqueous phase of milk (Fagan et al. 2006). The concentration of pectin has a strong influence on the microstructure and 

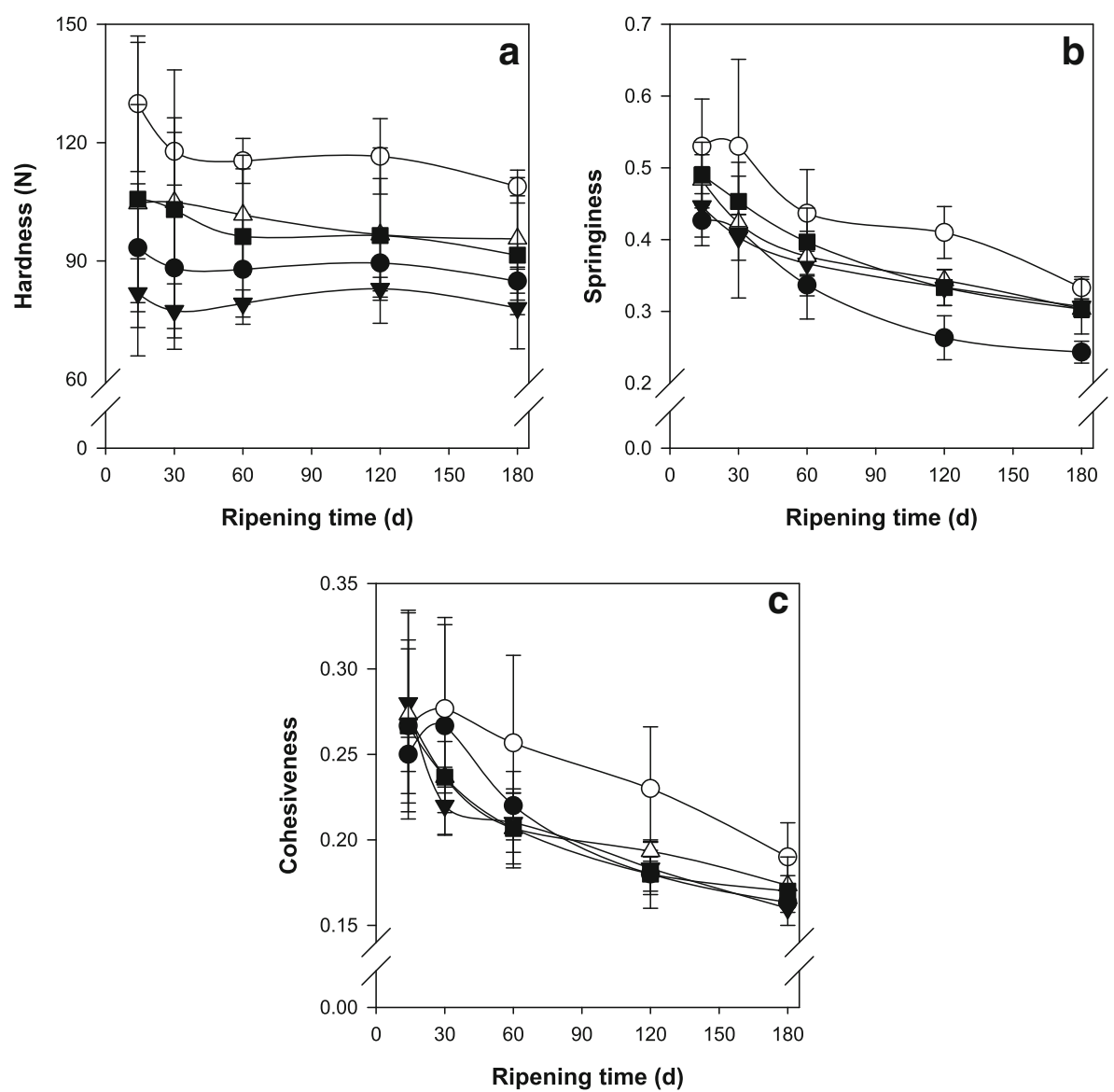

Fig. 6 Changes in TPA a hardness, $\mathbf{b}$ springiness, and $\mathbf{c}$ cohesiveness values during ripening full-fat control (filled circle), reduced-fat control (open circle), reduced-fat with amidated pectin (filled inverted triangle), high-methoxy pectin (open triangle), and low-methoxy pectin (filled square) Cheddar cheeses. Values are means of three replicates. Error bars indicate standard deviation

hence the rheological properties of rennet-induced gels. The results obtained from $\mathrm{RH}$ and RL are in agreement with Tan et al. (2007) who observed an increase in the stiffness of rennet gels and a reduction on syneresis as the concentration of HMP increased from $0 \%$ to $0.1 \%$ due to a more compact microstructure when observed by confocal laser microscopy. At higher concentrations of pectins $(0.12 \%-0.15 \%)$, a more open network of depleted caseins led to the conformation of a weaker gel (Acero Lopez et al. 2009), as was observed in RA rennet gel.

A reduction in the fat content of cheese leads to a shift in the compositional balance such as in moisture and protein content (Mistry 2001). The addition of pectin only led to an increase in the moisture content of RA cheese; however, moisture content of RL cheese is similar to both RF and RA cheeses. The capacity of AMP and LMP to form gels could increase the moisture content of experimental cheeses. However, amidation of LMP improves the gel-forming ability of AMP, leading to a reduction of syneresis (Thakur et al. 1997) that could increase the moisture content of RA cheese. Another 
Table 4 Mean squares, probabilities (in parenthesis) and $R^{2}$ values for textural analysis, melting properties, and release of free oil for experimental cheeses during 180 days of ripening

\begin{tabular}{|c|c|c|c|c|c|c|c|}
\hline Factor & $d f$ & Hardness & Springiness & Cohesiveness & $d f$ & Melting & Free oil \\
\hline \multicolumn{8}{|l|}{ Whole plot } \\
\hline Trial (T) & 2 & $\begin{array}{l}4993.6^{*} \\
(0.024)\end{array}$ & $\begin{array}{l}0.007109 \\
(0.319)\end{array}$ & $\begin{array}{l}0.0042893 \\
(0.223)\end{array}$ & 2 & $\begin{array}{l}44.27 \\
(0.725)\end{array}$ & $\begin{array}{l}7.44 \\
(0.448)\end{array}$ \\
\hline Treatment $(\mathrm{t})$ & 4 & $\begin{array}{l}3949.4 * \\
(0.028)\end{array}$ & $\begin{array}{l}0.024635^{*} \\
(0.032)\end{array}$ & $\begin{array}{l}0.0028280 \\
(0.380)\end{array}$ & 4 & $\begin{array}{l}548.21^{*} \\
(0.041)\end{array}$ & $\begin{array}{l}1859.30 * * \\
(<0.001)\end{array}$ \\
\hline $\begin{array}{l}\text { Error }(\mathrm{T} \times \mathrm{t}) \\
\text { Subplot }\end{array}$ & 8 & 810.9 & 0.005378 & 0.0023560 & 8 & 131.97 & 8.37 \\
\hline Age (A) & 4 & $\begin{array}{l}654.2 * * \\
(<0.001)\end{array}$ & $\begin{array}{l}0.081001 * * \\
(<0.001)\end{array}$ & $\begin{array}{l}0.0227513^{* *} \\
(<0.001)\end{array}$ & 3 & $\begin{array}{l}4656.97 * * \\
(<0.001)\end{array}$ & $\begin{array}{l}98.30 * * \\
(<0.001)\end{array}$ \\
\hline $\mathrm{A} \times \mathrm{t}$ & 16 & $\begin{array}{l}68.8 \\
(0.778)\end{array}$ & $\begin{array}{l}0.000905 \\
(0.764)\end{array}$ & $\begin{array}{l}0.0005780 \\
(0.508)\end{array}$ & 12 & $\begin{array}{l}101.61^{* *} \\
(0.005)\end{array}$ & $\begin{array}{l}12.05^{*} \\
(0.017)\end{array}$ \\
\hline Error & 40 & 94.4 & 0.001269 & 0.0005977 & 30 & 31.46 & 4.65 \\
\hline$R^{2}$ & & 0.89 & 0.91 & 0.85 & & 0.95 & 0.98 \\
\hline
\end{tabular}

Split-plot design with the five treatments (FF, RF, RA, RH, and RL) were analyzed as a discontinuous variable and trial was blocked. Subplot included the effect of aging of cheese (A) and the interaction age $\mathrm{x}$ treatment $(\mathrm{A} \times \mathrm{t})$ as variables. Degrees of freedom $(d f)$ differed for texture and functional properties as the time points for the analyses were different

$* 0.01<P \leq 0.05 ; * * P \leq 0.01$

explanation in the increment of moisture content could be associated with the amount of pectin added to cheesemilks, as HMP and LMP were added at $\leq 0.1 \%$ (w/w), comparing with AMP that was added at $0.175 \%(w / w)$. Lobato-Calleros et al. (2001) attributed an increase in the moisture content of low-fat Manchego cheese made from cheesemilks supplemented with LMP at levels of $0.2 \%(\mathrm{w} / \mathrm{w})$ to the water-binding
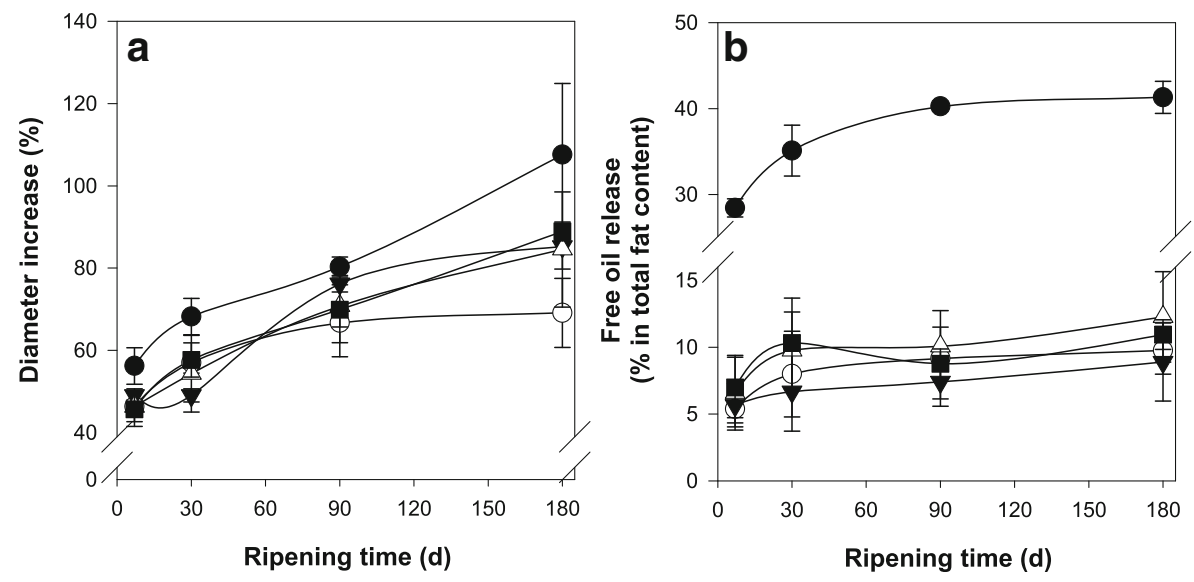

Fig. 7 Changes in a melting determined by the Schreiber test and $\mathbf{b}$ release of free oil values during ripening of full-fat control (filled circle), reduced-fat control (open circle), reduced-fat with amidated pectin (filled inverted triangle), high-methoxy pectin (open triangle), and low-methoxy pectin (filled square) Cheddar cheeses. Values are means of three replicates. Error bars indicate standard deviation 
Table 5 Rheological properties of experimental cheeses at 180 days of ripening determined by dynamic small amplitude oscillatory rheology

\begin{tabular}{|c|c|c|c|c|c|c|}
\hline \multirow[t]{2}{*}{ Item } & \multicolumn{6}{|l|}{ Treatment } \\
\hline & $\mathrm{FF}$ & $\mathrm{RF}$ & RA & $\mathrm{RH}$ & RL & SEM \\
\hline $\mathrm{G}^{\prime}$ at $20^{\circ} \mathrm{C}(\mathrm{Pa})$ & $37159.1^{\mathrm{bc}}$ & $43236.0^{\mathrm{a}}$ & $38466.7^{\mathrm{b}}$ & $34079.8^{\mathrm{c}}$ & $39394.1^{\mathrm{b}}$ & 873.0 \\
\hline $\mathrm{G}^{\prime}$ at $70^{\circ} \mathrm{C}(\mathrm{Pa})$ & $336.1^{\mathrm{bc}}$ & $538.5^{\mathrm{abc}}$ & $652.5^{\mathrm{a}}$ & $591.6^{\mathrm{ab}}$ & $290.2^{\mathrm{c}}$ & 43.1 \\
\hline $\mathrm{LT}_{\max }$ & $1.10^{\mathrm{a}}$ & $0.82^{\mathrm{b}}$ & $0.77^{\mathrm{bc}}$ & $0.73^{\mathrm{c}}$ & $1.17^{\mathrm{a}}$ & 0.05 \\
\hline Temperature at $\mathrm{LT}_{\max }\left({ }^{\circ} \mathrm{C}\right)$ & $67.18^{\mathrm{a}}$ & $65.89^{\mathrm{a}}$ & $62.42^{\mathrm{b}}$ & $62.89^{\mathrm{b}}$ & $66.12^{\mathrm{a}}$ & 0.52 \\
\hline
\end{tabular}

G' corresponds to storage modulus. $\mathrm{LT}_{\max }$ corresponds to loss tangent maximum. Data are means of three replicate trials. Means within the same row not sharing a common superscript differ $(P<0.05)$

capacity of pectin due to the formation of gels in the presence of calcium. Similar levels of total $\mathrm{Ca}$ probably resulted from the $\mathrm{pH}$ values at critical points during cheese manufacture being similar between treatments.

The proportion of INSOL Ca in Cheddar cheese is reduced during the first 30 days of ripening and remains constant beyond (Hassan et al. 2004). Differences in the proportion of INSOL Ca between RF with RA and RL cheeses could be attributed to gelation mechanisms of AMP and LMP. Lobato-Calleros et al. (2001) found the presence of calcium pectate particles when they observed the microstructure of low-fat Mexican Manchego cheese supplemented with LMP. Harte et al. (2007) proposed a gelation model of LMP during the acidification of milk that could also be applied to cheese. As $\mathrm{pH}$ decreases during acidification, solubilization of $\mathrm{Ca}$ from the colloidal calcium phosphate interacts with LMP, promoting cross linking of chains and hence the formation of a gel structure. This phenomenon probably occurred during cheese manufacture due to acidification of RA and RL cheesemilks caused by action of starter LAB.

An increment of cheese $\mathrm{pH}$ during ripening is attributed to the buffering capacity of cheese due to a reduction in the levels of INSOL Ca (Hassan et al. 2004; Table 2). In addition, $\mathrm{pH}$ plays an important role in the interaction between pectins and casein micelles. As previously stated, pectin remains dispersed in the serum phase of milk at neutral $\mathrm{pH}$, and it adsorbs onto casein micelles at $\mathrm{pH}$ 5.3. If the concentration of pectin is not enough to cover casein micelles, then pectin interacts with casein micelles by

Table 6 CIELAB color of experimental cheeses after 14 days of ripening

\begin{tabular}{|c|c|c|c|c|c|c|}
\hline \multirow[t]{2}{*}{ Item } & \multicolumn{6}{|c|}{ Treatment } \\
\hline & $\mathrm{FF}$ & $\mathrm{RF}$ & RA & $\mathrm{RH}$ & $\mathrm{RL}$ & SEM \\
\hline $\mathrm{L}^{*}$ & $83.45^{\mathrm{a}}$ & $78.34^{\mathrm{b}}$ & $78.57^{\mathrm{b}}$ & $79.71^{\mathrm{b}}$ & $78.80^{\mathrm{b}}$ & 0.564 \\
\hline$a^{*}$ & $-3.92^{\mathrm{ab}}$ & $-4.38^{\mathrm{b}}$ & $-3.40^{\mathrm{a}}$ & $-3.92^{\mathrm{ab}}$ & $-3.38^{\mathrm{a}}$ & 0.111 \\
\hline$b^{*}$ & $36.91^{\mathrm{a}}$ & $30.88^{\mathrm{ab}}$ & $27.71^{b}$ & $27.99^{\mathrm{b}}$ & $29.13^{\mathrm{b}}$ & 1.06 \\
\hline
\end{tabular}

Data are means of three replicate trials. Means within the same row not sharing a common superscript differ $(P<0.05)$

$L^{*}$ whiteness, $a^{*}$ greenness or redness, $b^{*}$ yellowness or blueness 
mean of bridging flocculation, whereas if casein micelles are fully covered by pectins, then they are sterically stabilized. However, a further increase in the pectin concentration leads to depletion interaction (Maroziene and de Kruif 2000). In addition, below $\mathrm{pH} 5.0$ pectin and casein micelles are associated by mean of electrosorption (Tuinier et al. 2002). These authors also indicated that renneting had no influence on the interaction of pectins and $\mathrm{K}$-casein depleted micelles. As the $\mathrm{pH}$ of pectin-added cheeses was close to 5.3, pectin may interact with the protein matrix by adsorption mechanisms, interrupting the compact protein structure, which will influence on water retention (i.e., higher moisture content, as occurred with RA cheese) and also cheese functionality. The use of carbohydrate-based fat replacers has shown a more open structure in low-fat cheeses, which might be caused by the presence of amorphous carbohydrate particles that interrupts the compact protein matrix (McMahon et al. 1996; Lobato-Calleros et al. 2001), altering the composition, texture, and functionality (Mistry 2001).

Similarities in the counts of LAB between treatments could be explained due to similar levels of MNFS (Table 2). Fenelon et al. (2000) found a reduction in the counts of starter LAB, which was attributed to a decrease in the MNFS as fat content was reduced. As NSLAB likely use the milk fat globule membrane as a source of carbon for their growth (Fox et al. 1998), it would have been expected that propagation of NSLAB would be lower in reduced-fat cheeses.

Similar levels of primary proteolysis between FF and reduced-fat cheeses can be related to their similar levels of MNFS (Table 2). A significant increment in the levels of $\mathrm{pH}$ 4.6 SN/TN as the fat content of cheese was increased has been associated with a concomitant increment of MNFS that may lead to a higher retention of chymosin (Guinee et al. 2000; Fenelon et al. 2000). An increase in the levels of FAA has been previously reported for low-fat cheese (Fenelon et al. 2000), which is attributed to a concomitant increase of the protein content as the fat content is reduced (Guinee et al. 2000).

The hydrophobic peptide $\beta-\mathrm{CN}$ (f193-209) formed by cleavage at $\mathrm{Leu}_{192}-\mathrm{Tyr}_{193}$ which also forms $\beta-\mathrm{CN}$ (f1-189/192), contributes bitterness to cheese (Visser et al. 1983). The concentration of salt to moisture content (S/M) has a direct influence on the residual activity of chymosin. We observed lower levels of $\mathrm{S} / \mathrm{M}$ in reduced-fat cheeses, which might increase the accumulation of $\beta-\mathrm{CN}$ (f1-189/192) due to an enhancement of the residual activity (Fenelon and Guinee 2000). As previously stated, higher accumulation of $\beta$-CN (f1-189/192) in RA can also be influenced by its lower $\mathrm{pH}$. Fenelon and Guinee (2000) found a lower degradation of $\alpha_{\mathrm{s} 1}-\mathrm{CN}$ as the fat content of cheese is reduced, due to a decrease of residual activity of chymosin. In our study, similar levels of intact $\alpha_{\mathrm{s} 1}-\mathrm{CN}$ between treatments could be associated with similar levels in the MNFS (Table 2), which influences in the residual activity of chymosin.

The softening of cheese during ripening is partly associated to the extent of proteolysis, mainly caused by the degradation of $\alpha_{\mathrm{s} 1}$-casein (Fig. 5b; Creamer and Olson 1982). In addition, the reduction of the INSOL Ca levels during ripening (Table 2), which corresponds to the release of colloidal calcium phosphate (CCP) to the serum phase, has a strong influence on cheese hardness, causing a weakening of the protein matrix (Lucey et al. 2003). An increase in TPA hardness as the fat content is reduced is attributed to a concomitant increase in the protein content (Fenelon and Guinee 2000) and also to a decrease in the interruption of the cheese matrix by fat globules, leading to a more compact structure (Bryant et al. 1995; Johnson et al. 2009). 
As previously stated, the addition of pectin may cause an interruption of the cheese matrix, probably due to protein polysaccharide interactions (Maroziene and de Kruif 2000; Tuinier et al. 2002) and or the formation of calcium pectate gels (Lobato-Calleros et al. 2001), conferring a less compact structure and hence reduce hardness. A similar effect has been reported by McMahon et al. (1996) who observed the presence of amorphous carbohydrate-based fat replacers immersed in the cheese matrix. In addition, lower levels of INSOL Ca, when compared to RF, was found in RA and RL cheeses (Table 2), probably due to the formation of calcium pectate gels (LobatoCalleros et al. 2001; Harte et al. 2007) that might contribute to a softer texture. The addition of AMP was more efficient in reducing hardness, leading to similar values than FF, probably caused by higher concentrations of pectin added than in the other treatments. An increase in springiness as the fat content is reduced was also observed by Lobato-Calleros et al. (2001). These authors also found a reduction in the springiness of reduced-fat Manchego cheese with LMP added when compared to control which was attributed to an interruption of the protein matrix by pectin particles. The same effect in the protein matrix might have caused a reduction of springiness in RA, RH, and RL cheeses, when compared to RF. Bryant et al. (1995) observed an increase in the cohesiveness of Cheddar cheese as the fat content was lower than $21 \%$. On the other hand, Tunick et al. (1991) found that higher moisture content in Mozzarella cheese is associated to higher cohesiveness values. In our study, we found no differences in the cohesiveness of experimental cheeses, which could be explained by higher moisture content of reduced-fat cheeses, when compared to FF (Table 2) and also with the presence of fat replacers, i.e., pectin, that would reduce casein-casein interactions, leading to a loosening of the protein matrix (Lobato-Calleros et al. 2001).

An increase of melting during ripening for all cheeses is associated to the extent of proteolysis (Fig. 3) and changes in levels of INSOL Ca (Table 2; Lucey et al. 2003). A lower melting in reduced-fat cheeses is associated to a higher protein content that leads to a more compact structure (Guinee et al. 2000). In addition, levels of free oil release might also be influenced by the melting properties (Fig. 7b). Rudan and Barbano (1998) observed the formation of a thick skin and/or blisters during the baking of lowfat Mozzarella cheese that prevented its softening, and hence flow, due to dehydration of the surface caused by a lack of free oil release that may act as a hydrophobic surface coating. To avoid this problem, the authors found that covering the surface of cheese with a small amount of a hydrophobic surface coating considerably improved its melting properties. As previously stated, a more open structure due to the addition of pectin may eventually increase melting (McMahon et al. 1996). A higher meltability found in cheeses containing pectin could also be attributed to lower levels of INSOL Ca at 180 days of ripening, when compared to control (Table 2), due to a lower amount of CCP crosslinks, that leads to a reduction in the attractive interactions of the cheese matrix (Lucey et al. 2003).

A decrease in storage modulus $\left(G^{\prime}\right)$ during heating of cheese indicates a weakening of the casein matrix structure (Lucey et al. 2003). A higher $\mathrm{G}^{\prime}$ value in $\mathrm{RF}$ at $20{ }^{\circ} \mathrm{C}$ is probably associated to higher protein content. Lower G' values found in cheeses containing pectin could be associated with a more open structure (McMahon et al. 1996; LobatoCalleros et al. 2001) and lower levels of INSOL Ca (Table 2). During the heating of cheese at high temperatures ( $>$ temperature at $\mathrm{LT}_{\max }$ ), Udayarajan et al. (2005) observed an increase in $\mathrm{G}^{\prime}$ probably caused by a heat-induced formation of INSOL Ca that may 
interact with caseins to form new structures. This same phenomenon might have caused increments of $\mathrm{G}^{\prime}$ values in RA and $\mathrm{RH}$ cheeses at $70{ }^{\circ} \mathrm{C}$, due to a lower temperature at $\mathrm{LT}_{\text {max }}$. The LT values at temperatures $<40{ }^{\circ} \mathrm{C}$ (results not shown) were constant for all treatments (0.3-0.4), indicating the presence of a solid-like matrix. At higher temperatures, the LT values increased to a maximum $\left(\mathrm{LT}_{\max }\right.$ ) reached at $60-70{ }^{\circ} \mathrm{C}$ (Table 5) to then decrease at higher temperatures (results not shown). Higher LT values relate to a higher melting (Lucey et al. 2003). As expected, RF had a lower $\mathrm{LT}_{\max }$ than FF. Only RL exhibited a similar $\mathrm{LT}_{\max }$ than FF cheese, whereas RA and RH had similar values to RF. A lower temperature at $\mathrm{LT}_{\max }$ found in $\mathrm{RA}$ and $\mathrm{RH}$ cheeses could be associated to a combined effect in the levels of INSOL Ca and the extent of proteolysis. However, Udayarajan et al. (2005) found that $\mathrm{LT}_{\max }$ is highly frequency dependent, and hence, these authors suggest caution in using this parameter as melting index. We observed differences in the results obtained between the Schreiber melting test and dynamic small amplitude rheology. Cooke et al. (2013) studied the melting properties of full-fat and reduced-fat Cheddar cheese made from milk supplemented with gum tragacanth and attributed these differences to a higher extent of fat liquefaction in the Schreiber test due to the high temperatures of exposure of cheese samples. In addition, these authors suggested the presence of interactions between casein and gum tragacanth that inhibited cheese melting at the temperatures of dynamic small amplitude rheology. This type of interactions may also inhibit cheese melting in pectin-containing cheeses.

In unmelted cheese, fat acts to scatter light and a reduction in fat content leads to a translucent appearance, which is reflected by a reduction in whiteness (Johnson et al. 2009). A decrease of cheese whiteness during ripening could be attributed to an increase in proteolysis (Fig. 3) and also a decrease in INSOL Ca levels (Table 2). The addition of pectin had no effect on cheese whiteness; however, greenness of RA and RL cheeses was reduced (Table 6). This finding was not expected as we assumed that pectin would act as a light scatter center and hence increase whiteness.

\section{Conclusions}

Depending on the type of pectin, its addition to milks for the manufacture of reducedfat Cheddar cheese had to be below certain concentration in order to prevent phase separation due to depletion flocculation. Amidated pectin had an impact on $\mathrm{pH}$ and composition of experimental cheeses, by increasing the moisture content due to its water holding capacity. The levels of INSOL Ca were modified by the use of AMP and LMP, probably due to the formation of calcium pectate structures that influenced on texture and meltability. The addition of pectin had no effect in the number of LAB and NSLAB during ripening, when compared to reduced-fat control. The TPA hardness was significantly reduced in cheeses supplemented with pectins, especially RA. Melting properties of reduced-fat cheeses were modified when analyzed by Schreiber melting test and dynamic small amplitude rheology. Pectin had no effect in the whiteness of cheeses, when compared to RF. These results suggest that the use of pectin might be a useful strategy to modify the composition, texture, and functionality of reduced-fat Cheddar cheeses. However, interactions of proteinpolysaccharides also have to be considered as a disadvantage, due to phase separations prior rennet coagulation. 
Acknowledgments We would like to thank the Herbstreith \& Fox Corporate Group (Neuenbürg/Wütt, Germany) for its donation of pectins used in this study.

\section{Compliance with ethical standards}

Funding Rodrigo A. Ibáñez is funded by a grant from the Chilean National Commission for Scientific and Technological Research, CONICYT.

Conflict of interest The authors declare that they have no competing interests.

\section{References}

Acero Lopez A, Corredig M, Alexander M (2009) Diffusing wave and ultrasonic spectroscopy of rennetinduced gelation of milk in the presence of high-methoxyl pectin. Food Biophys 4:249-259

Altan A, Turhan M, Gunasekaran S (2005) Short communication: comparison of covered and uncovered Schreiber test for cheese meltability evaluation. J Dairy Sci 88:857-861

Andrews AT (1983) Proteinase in normal bovine milk and their action on caseins. J Dairy Res 50:45-55

Blakesley RW, Boezi JA (1977) A new staining technique for proteins in polyacrylamide gels using Coomassie brilliant blue G250. Anal Biochem 82:580-582

Bourne MC (1978) Texture profile analysis. Food Technol 32:62-66,72

Bryant A, Ustunol Z, Steffe J (1995) Texture of Cheddar cheese as influenced by fat reduction. J Food Sci 60: 1216-1219

Childs JL, Drake M (2009) Consumer perception of fat reduction in cheese. J Sens Stud 24:902-921

Cooke DR, Khosrowshahi A, McSweeney PLH (2013) Effect of gum tragacanth on the rheological and functional properties of full-fat and half-fat Cheddar cheese. Dairy Sci Technol 93:45-62

Creamer LK, Olson NF (1982) Rheological evaluation of maturing Cheddar cheese. J Food Sci 47:631-636

Fagan CC, O'Donnell CP, Cullen PJ, Brennan CS (2006) The effect of dietary fibre inclusion on milk coagulation kinetics. J Food Eng 77:261-268

Fenelon MA, Guinee TP (2000) Primary proteolysis and textural changes during ripening in Cheddar cheeses manufactured to different fat contents. Int Dairy J 10:151-158

Fenelon MA, O'Connor P, Guinee TP (2000) The effect of fat content on the microbiology and proteolysis in cheddar cheese during ripening. J Dairy Sci 83:2173-2183

Fox PF (1963) Potentiometric determination of salt in cheese. J Dairy Sci 46:744-745

Fox PF, McSweeney PLH, Lynch CM (1998) Significance of non-starter lactic acid bacteria in cheddar cheese. Aust J Dairy Technol 52:83-89

Guinee TP, Auty MA, Fenelon MA (2000) The effect of fat content on the rheology, microstructure and heatinduced functional characteristics of Cheddar cheese. Int Dairy J 10:277-288

Harte FM, Montes C, Adams M, San Martin-Gonzalez MF (2007) Solubilized micellar calcium induced low methoxyl-pectin aggregation during milk acidification. J Dairy Sci 90:2705-2709

Hassan A, Johnson ME, Lucey JA (2004) Changes in the proportions of soluble and insoluble calcium during the ripening of Cheddar cheese. J Dairy Sci 87:854-862

IDF (1982) Cheese and processed cheese. Determination of the total solids content. In: Standard 4A

IDF (1986) Determination if the nitrogen content (Kjeldalh method) and calculation of crude protein. Standard $20 \mathrm{~A}$.

IDF (2007) Milk and milk products. Determination of calcium, sodium, potassium and magnesium content. Atomic absorption spectrometric method. Standard 119

IIRS (1955) Determination of the percentage of fat in cheese. Irish Standard 69

Johnson ME, Kapoor R, Mcmahon DJ et al (2009) Reduction of sodium and fat levels in natural and processed cheeses: scientific and technological aspects. Compr Rev Food Sci Food Saf 8:252-268

Kindstedt PS, Fox PF (1991) Modified Gerber test for free oil in melted mozzarella cheese. J Food Sci 56: 1115-1116

Kruchoo CNF, Fox PF (1982) Soluble nitrogen in Cheddar cheese. Milchwissenschaft 37:331-335

Kruchoo CN, Rahilly J, Fox PF (1983) Assessment of proteolysis in cheese by reaction with trinitrobenzene sulphonic acid. Irish J Food Sci Technol 7:129-133 
Lobato-Calleros C, Robles-Martínez JC, Caballero-Pérez JF, Aguirre-Mandujano E (2001) Fat replacers in low-fat Mexican Manchego cheese. J Texture Stud 32:1-14

Lucey JA, Johnson ME, Horne DS (2003) Invited review: perspectives on the basis of the rheology and texture properties of cheese. J Dairy Sci 86:2725-2743

Maroziene A, de Kruif CG (2000) Interaction of pectin and casein micelles. Food Hydrocoll 14:391-394

McMahon DJ, Alleyne MC, Fife RL, Oberg CJ (1996) Use of fat replacers in low fat Mozzarella cheese. J Dairy Sci 79:1911-1921

Mistry VV (2001) Low fat cheese technology. Int Dairy J 11:413-422

Montgomery DC (2013) Design and analysis of experiments. Wiley, Hoboken

Rogosa M, Mitchell JA (1951) A selective medium for the isolation and enumeration of oral and faecal lactobacilli. J Bacteriol 62:132-133

Rudan MA, Barbano DM (1998) A model of Mozzarella cheese melting and browning during pizza baking. J Dairy Sci 81:2312-2319

Tan YL, Ye A, Singh H, Hemar Y (2007) Effects of biopolymer addition on the dynamic rheology and microstructure of renneted skim milk systems. J Texture Stud 38:404-422

Terzaghi BE, Sandine AWE (1975) Improved medium for lactic streptococci and their bacteriophages. Appl Microbiol 29:807-813

Thakur BR, Singh RK, Handa AK, Rao MA (1997) Chemistry and uses of pectin — a review. Crit Rev Food Sci Nutr 37:37-41

Tuinier R, Rolin C, de Kruif CG (2002) Electrosorption of pectin onto casein micelles. Biomacromolecules 3: 632-638

Tunick MH, Mackey KL, Smith PW, Holsinger VH (1991) Effects of composition and storage on the texture of mozzarella cheese. Neth Milk Dairy J 45:117-125

Udayarajan CT, Lucey JA, Horne DS (2005) Use of Fourier transform mechanical spectroscopy to study the melting behaviour of cheese. J Texture Stud 36:489-515

Visser S, Hup G, Exterkate FA, Stauhouders J (1983) Bitter flavour in cheese. 2. Model studies on the formation and degradation of bitter peptides by proteolytic enzymes from calf rennet, starter cells and starter cell fractions. Neth Milk Dairy J 37:169-180 